\title{
Histone acetyltransferase p300/CBP inhibitor C646 blocks the survival and invasion pathways of gastric cancer cell lines
}

\author{
YA-MEI WANG ${ }^{1,2}$, MENG-LI GU ${ }^{1}$, FAN-SHENG MENG ${ }^{3}$, \\ WEN-RUI JIAO ${ }^{1}$, XIN-XIN ZHOU ${ }^{1}$, HANG-PING YAO ${ }^{4}$ and FENG JI ${ }^{1}$
}

\begin{abstract}
${ }^{1}$ Department of Gastroenterology, The First Affiliated Hospital, College of Medicine, Zhejiang University, Hangzhou, Zhejiang 310009; ${ }^{2}$ Department of Gastroenterology, The Fourth Affiliated Hospital of Zhejiang University School of Medicine, Yiwu, Zhejiang 322000; ${ }^{3}$ Department of Gastroenterology, Linyi People's Hospital, Linyi, Shandong 276000; ${ }^{4}$ State Key Laboratory for Diagnosis and Treatment of Infectious Diseases, The First Affiliated Hospital, College of Medicine, Zhejiang University, Hangzhou, Zhejiang 310009, P.R. China
\end{abstract}

Received April 20,2017; Accepted September 15, 2017

DOI: 10.3892/ijo.2017.4176

\begin{abstract}
The histone acetyltransferases (HATs) adenovirus E1A-associated protein (p300) and CREB binding protein (CBP) serve as coactivators during a diverse assortment of cellular processes. In the present study, p300 and CBP were highly expressed in 5 gastric cancer (GC) cell lines (SGC-7901, MKN45, MGC-803, BGC-823 and KATO III) compared with human normal gastric epithelial cell line (GES-1). C646, a selective inhibitor of p300 and CBP, inhibited cell viability and cell cycle and promoted cell apoptosis in all 5 GC cell lines. In addition, $\mathrm{C} 646$ suppressed the migration and invasion capability of the GC cell lines, except for the middle-differentiated SGC-7901 cell line. Furthermore, we detected the differential expression of corresponding oncogenic signalling molecules, such as c-Met, Akt, Bcl-2, Bax, cyclin D1, MMP7 and MMP9, in GC cells following C646 treatment. In conclusion, our results suggest that $\mathrm{C} 646$ inhibits the acetylation of histone $\mathrm{H} 3$ via inactivation of p300 and CBP, resulting in antineoplastic effects toward GC cells. Thus, the selective HAT inhibitor C646 could be a promising antitumour reagent for GC treatment.
\end{abstract}

\section{Introduction}

Gastric cancer (GC) is one of the most common carcinomas and the third major contributor to cancer mortality worldwide (1). However, the molecular mechanisms involved in the oncogenesis and progression of GC have not yet been fully

Correspondence to: Professor Feng Ji, Department of Gastroenterology, The First Affiliated Hospital, College of Medicine, Zhejiang University, 79 Qing Chun Road, Hangzhou, Zhejiang 310003, P.R. China

E-mail: jifeng@zju.edu.cn

Key words: gastric cancer, histone acetyltransferase, E1A-associated protein, CREB binding protein, C646 understood. Despite the fact that the improvements in medical and surgical therapy have lowered the mortality of GC during the past few decades, the 5-year survival rate for patients with advanced GC remains unsatisfactory at less than $10-25 \%(2,3)$. Thus, a detailed molecular understanding of GC pathogenesis and selective therapeutic targets for GC patients are urgently needed.

The histone acetyltransferases p300 and CBP are large (300 kDa) modular proteins. p300 and CBP share 63\% identical amino acid sequences and have very similar functions. Consequently, these histone acetyltransferases are together considered p300/CBP (4). p300/CBP play crucial roles in the cell cycle, DNA synthesis, cellular differentiation and organ development (4-8). In solid tumours, such as human prostate cancer ( $\mathrm{PCa}), \mathrm{p} 300 / \mathrm{CBP}$ are upregulated and induce the gene transcription of the androgen receptor (AR), which is a key PCa promoter (9-11). However, the inhibition of p300/CBP decreases the proliferation and invasive capacity of prostate cancer cells (9-11). In the colon cancer cell line HCT116, the absence of p300 increases the apoptosis in response to different forms of DNA damage (12). Additionally, the p300/CBP genes are upregulated in melanoma cell lines (13) and participate in the regulation of melanocyte lineage-specific MITF transcription factor, which is associated with antiapoptosis, angiogenisis and metastasis in melanomas (14-16). In pancreatic cancer, p300 is also involved in controlling the migratory and invasive behaviour of the tumours and inactivation of p300 blocks the migration of pancreatic cancer cells (17). Recently, p300 was reported to be involved in the epithelial to mesenchymal transition (EMT) in the human GC cell line BGC-823 (18). Nevertheless, whether p300/CBP could serve as potential antineoplastic targets for GC remains unclear.

C646, a small molecule inhibitor of p300/CBP, exerts antitumour activity in many cancer cell lines $(11,19)$. However, its effects on GC cells and the mechanisms underlying these effects have not been extensively studied. In the present study, we investigated the therapeutic effects of the HAT inhibitor C646 on several GC cell lines and further explored the potential mechanisms underlying its antitumour activity. 


\section{Materials and methods}

Cell lines. The normal human gastric epithelial cell line GES-1 and the human GC cell lines SGC-7901 (moderately differentiated), MKN45 (poorly differentiated), BGC-823 (undifferentiated) and KATO III (signet-ring cell) were purchased from the American Type Culture Collection (ATCC; Manassas, VA, USA). The human GC cell line MGC-803 (poorly differentiated) was obtained from the Type Culture Collection of the Chinese Academy of Sciences (Shanghai, China). All the cell lines were cultured in RPMI-1640 medium (Corning Inc., Corning, NY, USA) supplemented with $10 \%$ fetal bovine serum (FBS; Gibco, Carlsbad, CA, USA) and $1.0 \%$ penicillin/streptomycin (Gibco) at $37^{\circ} \mathrm{C}$ in a humidified atmosphere of $95 \%$ air and $5 \% \mathrm{CO}_{2}$.

Quantitative real-time polymerase chain reaction ( $q R T-P C R)$. The total RNA of each cell line was extracted using TRIzol ${ }^{\mathrm{TM}}$ reagent (Invitrogen, Carlsbad, CA, USA) according to the manufacturer's protocol. qRT-PCR was conducted as previously described (20). The primer sequences were as follows: c-Met, forward, 5'-TTTCAAATGGCCACGGGACAACA CA-3' and reverse, 5'-TGGGCTGGGGTATAACATTCAA GA-3'; MMP7, forward, 5'-GATGGTAGCAGTCTAGGGAT TAACTTC-3' and reverse, 5'-GGAATGTCCCATACCCAAA GAA-3'; MMP9, forward, 5'-CACGCAC GACGTCTTCCA-3' and reverse, 5'-AAGCGGTCCTGGCAGAAAT-3' (Sangon Biotech Co., Ltd., Shanghai, China). Gene copy number was calculated using the $\Delta \Delta \mathrm{Ct}$ method.

Western blot analysis. The total protein from each cell line was lysed using cell lysis buffer (Cell Signaling Technology, Danvers, MA, USA), according to the manufacturer's instructions. Western blotting was performed as previously described (21). Rabbit antibodies corresponding to acetylated histone H3 (Ac-H3, acetyl K18) and total histone H3 were purchased from Abcam (Cambridge, UK). Antibodies against c-Met, total Akt, phospho-Akt (Ser473), PARP and glyceraldehyde-3-phosphate dehydrogenase (GAPDH) were purchased from Cell Signaling Technology.

Cell Counting kit-8 (CCK-8) assay. Normal gastric epithelial cells and 5 GC cell lines were seeded in 96-well plates at $0.8-1.0 \times 10^{4}$ cells/well (in $100 \mu 1$ complete RPMI-1640). After attachment, the cells were washed and replaced with fresh RPMI-1640 medium containing 1\% FBS. Thereafter, C646 (Selleck Chemicals, Houston, TX, USA) at the required concentrations was added to the wells. Twenty-four hours later, $\sim 10 \mu \mathrm{l}$ of CCK-8 dye was added to each well, and the plate was incubated for 1-3 $\mathrm{h}$. The optical density (OD) was measured at $450 \mathrm{~nm}$ with a microplate reader (Bio-Rad Laboratories, Hercules, CA, USA).

Cell cycle assay and cell apoptosis assay. Cells were plated in 6-well plates at $3 \times 10^{5}$ cells/well. Twenty-four hours later, the cells were treated with C646 $10 \mu \mathrm{mol} / 1$ for $6 \mathrm{~h}$ (for the cell cycle assay) or $24 \mathrm{~h}$ (for the cell apoptosis assay). Then, cell cycle assay and cell apoptosis assay were performed as previously described (20).
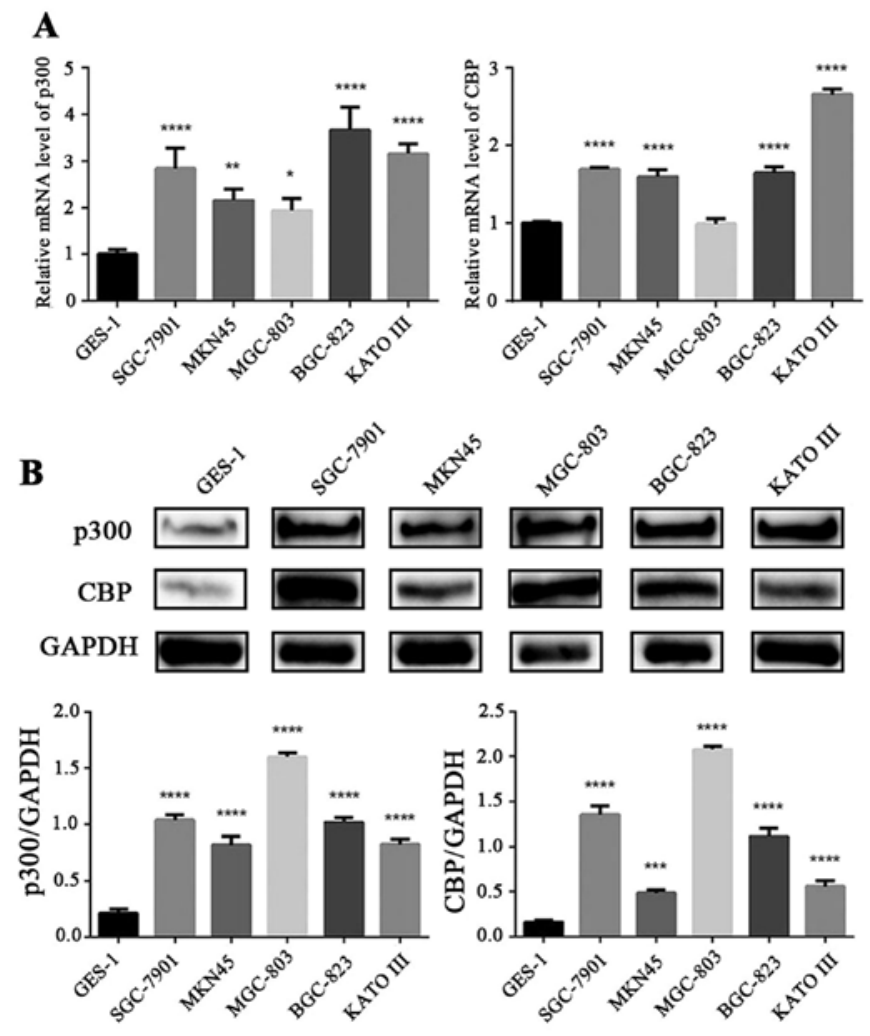

Figure 1. p300/CBP are overexpressed in GC cells compared with normal gastric epithelial cells. (A) Quantitative real-time PCR was conducted to evaluate the mRNA expression levels of $p 300 / C B P$ in normal gastric epithelial cell line and 5 GC cell lines. (B) The protein expression levels of p300/CBP in normal gastric epithelial cells and GC cells were detected by western blotting. GAPDH was used as a reference. The data shown are the means $\pm \mathrm{SD}$ of three independent experiments $\left({ }^{*} \mathrm{P}<0.05,{ }^{* *} \mathrm{P}<0.01\right.$ ***** $\mathrm{P}<0.0001$ vs. the GES-1 group).

Wound healing assay. After treatment with C646 (10 $\mu \mathrm{mol} / \mathrm{l})$ for $24 \mathrm{~h}$, cells were equally seeded in a 12-well plate. After attachment, a monolayer wound was introduced using a $10-\mu 1$ pipette tip. The cells were washed with phosphate-buffered saline (PBS) to remove floating debris, and the vertical distance between both sides of the wound in at least three distinct randomly selected areas was measured at 0 and $24 \mathrm{~h}$ after wound injury using Image-Pro Plus 6.0 software.

Transwell assay. Following treatment with C646 (10 $\mu \mathrm{mol} / \mathrm{l})$ for $24 \mathrm{~h}, 2.5 \times 10^{4}$ cells/well were seeded into 24 -well chambers (Corning) in 1\% FBS medium and 10\% FBS medium was added to the lower wells. After 6 or $24 \mathrm{~h}$ of incubation, the cells remaining in the upper chamber were carefully removed with cotton swabs. Migrated cells on the bottom side of the membrane were stained with crystal violet for $15 \mathrm{~min}$. Migrated cells were counted in at least 5 randomly selected fields.

Statistical analyses. GraphPad Prism 6 (GraphPad Software, Inc., San Diego, CA, USA) was used for all analyses. Continuous data are expressed as the means \pm standard deviations. Statistical analyses were performed using a one-way ANOVA in cases in which multiple comparisons were performed. Student's t-test was performed to compare the mean differences between the two groups. $\mathrm{P}<0.05$ was considered significant. All experiments were performed in triplicate. 

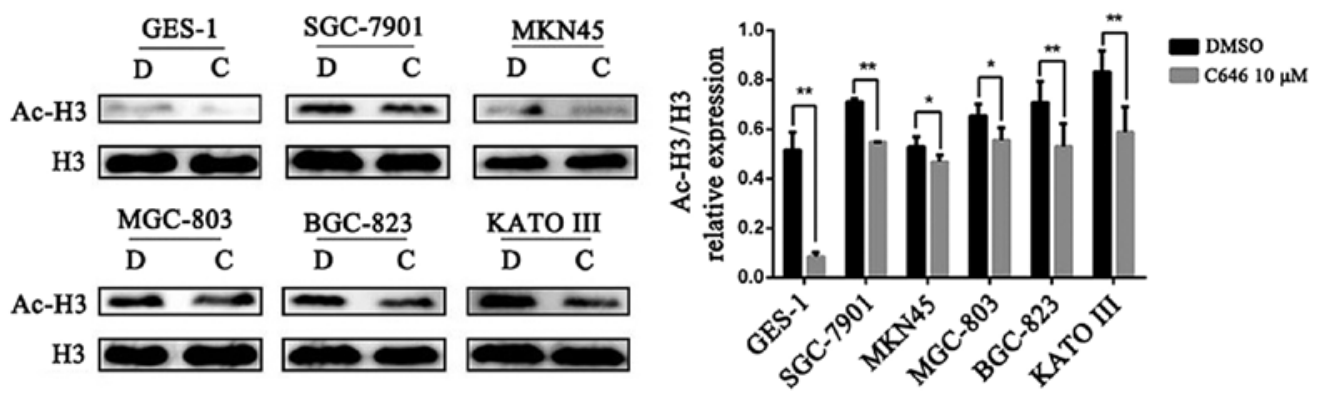

Figure 2. C646 treatment reduced the acetylation of histone H3 in both GC cells and normal gastric epithelial cells. GC cells and GES-1 cells were treated with C646 $10 \mu \mathrm{mol} / 1$ for $6 \mathrm{~h}$, DMSO was used as a control. Western blotting was performed to detect the expression level of acetylated histone H3. Total histone $\mathrm{H} 3$ was used as a reference. The data shown are means $\pm \mathrm{SD}$ of three independent experiments $\left(" \mathrm{P}<0.05,{ }^{* *} \mathrm{P}<0.01\right.$ vs. DMSO group). Ac- $\mathrm{H} 3$, acetylated histone H3; H3, total histone H3; D, DMSO; C, C646.

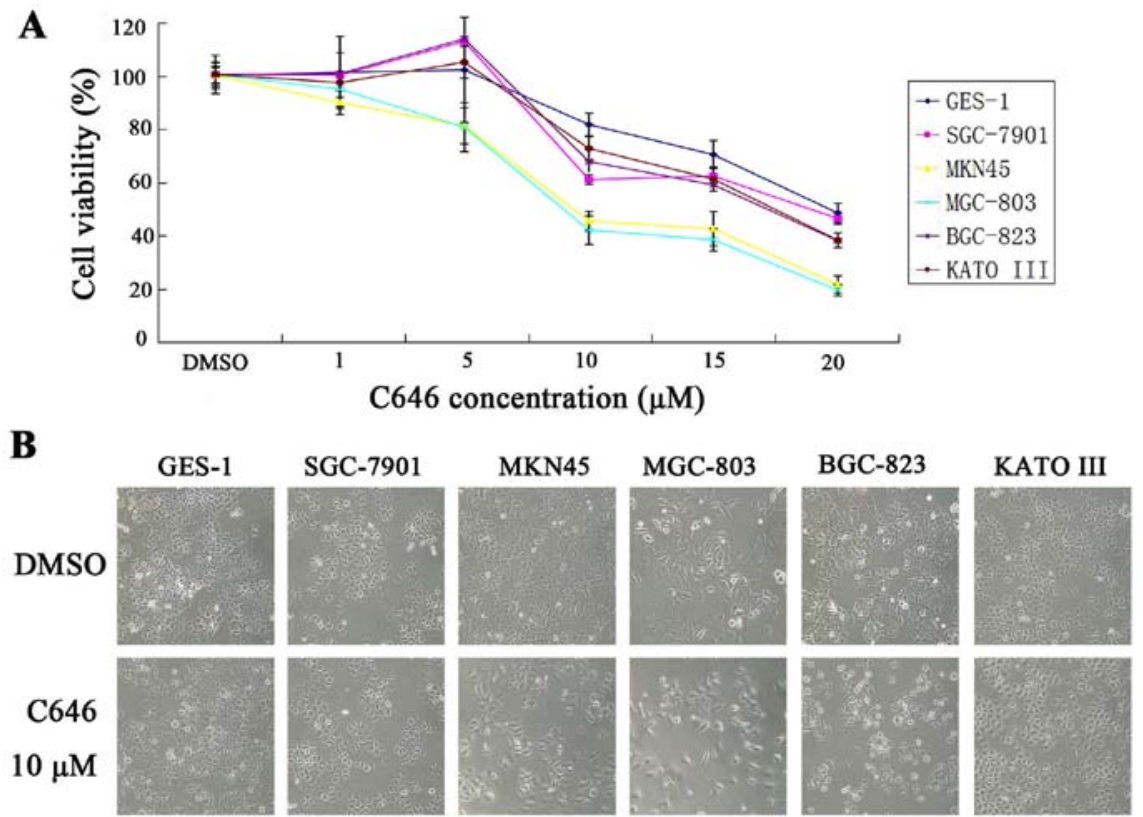

Figure 3. C646 inhibits the cell growth of normal gastric epithelial cell line and 5 GC cell lines. (A) Normal gastric epithelial cells and GC cells were treated with different concentrations of C646 for $24 \mathrm{~h}$. Cell viability was quantified with the Cell Counting kit-8 (CCK-8). The data shown are the means \pm SD of three independent experiments $(\mathrm{P}<0.05, \mathrm{P}<0.01, \mathrm{P}<0.0001$ vs. the DMSO group). (B) The cell morphology of the $5 \mathrm{GC}$ cell lines was assessed after exposure to $10 \mu \mathrm{mol} / 1 \mathrm{C} 646$ for $24 \mathrm{~h}$ (original maginification, $\mathrm{x} 200$ ).

\section{Results}

p300/CBP are upregulated in GC cells compared with normal gastric epithelial cells. We examined the gene and protein expression of $\mathrm{p} 300 / \mathrm{CBP}$ in normal gastric epithelial cell line (GES-1) and 5 GC cell lines (SGC-7901, MKN45, MGC-803, BGC-823 and KATO III) via qRT-PCR and western blotting. As shown in Fig. 1A, the mRNA levels of $p 300$ were highly expressed in the $5 \mathrm{GC}$ cell lines compared with the normal gastric epithelial cell line $(\mathrm{P}<0.05)$. Except for the MGC-803 cell line, the $C B P$ mRNA levels in the other four GC cell lines were significantly higher than those in the GES-1 cells $(\mathrm{P}<0.0001)$. The protein expression levels of $\mathrm{p} 300 / \mathrm{CBP}$ in the $5 \mathrm{GC}$ cell lines were significantly higher than those in the GES-1 cells $(\mathrm{P}<0.001)$ (Fig. 1B).

C646 reduces histone H3 acetylation. C646 is a selective inhibitor of $\mathrm{p} 300 / \mathrm{CBP}$, which control the acetylation of histone $\mathrm{H} 3(22,23)$. In the present study, the acetylation of histone H3 was detected to verify the effect of C646 on normal gastric epithelial cells and GC cells. All 6 cell lines were treated with dimethyl sulfoxide (DMSO) or C646 $10 \mu \mathrm{mol} / 1$ for $6 \mathrm{~h}$. We found that C646 treatment significantly reduced the levels of histone $\mathrm{H} 3$ acetylation in both GC cells and normal gastric epithelial cells $(\mathrm{P}<0.05)$. In addition, the basal acetylated histone H3 (Ac-H3) expression level of the GES-1 cell line was lower than that of the GC cell lines (Fig. 2).

C646 inhibits cell viability and cell cycle and promotes cell apoptosis in GC cells. As demonstrated above, p300/CBP were overexpressed in $5 \mathrm{GC}$ cell lines compared with normal gastric epithelial cells. To investigate the effects of $\mathrm{p} 300 / \mathrm{CBP}$ inhibition, both normal gastric epithelial cells and GC cell lines were treated with an increasing concentration of C646 $(1,5,10,15$ and $20 \mu \mathrm{mol} / \mathrm{l})$ for $24 \mathrm{~h}$. As shown in Fig. 3A, the cell viability of GES-1 cells was not significantly inhibited when the cells were treated with C646 at 1,5 or $10 \mu \mathrm{mol} / 1$. However, when the cells were treated with 15 or $20 \mu \mathrm{mol} / 1$ 

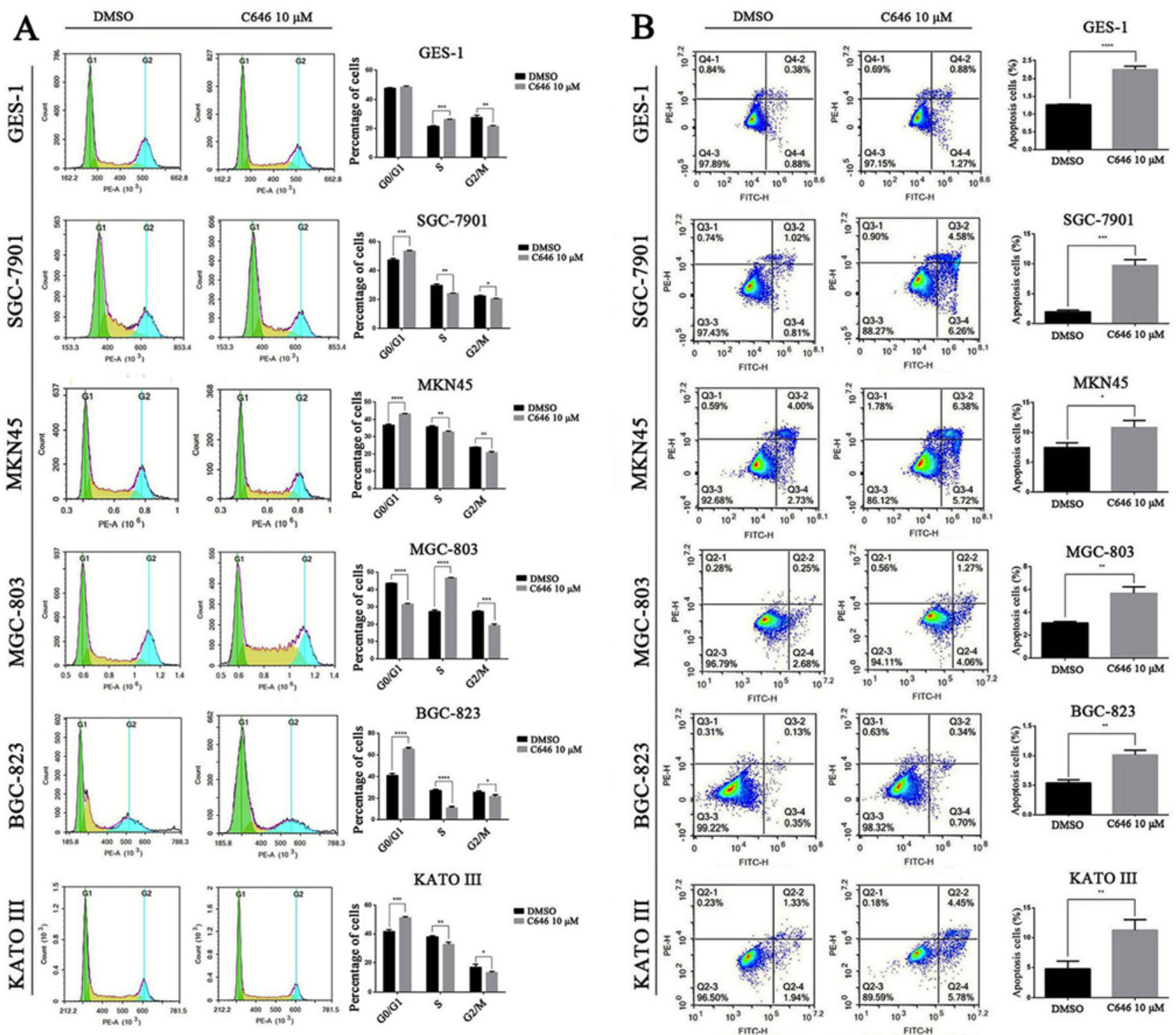

(A) cell cycle and promotes cell apoptosis of normal gastric epithelial cells and GC cells. (A) Cell cycle was detected by flow cytometric analysis after cells were treated with C646 at $10 \mu \mathrm{mol} / 1$ for $6 \mathrm{~h}$. (B) Cells were treated with $10 \mu \mathrm{mol} / 1 \mathrm{C} 646 \mathrm{for} 24 \mathrm{~h}$ before flow cytometric analysis was performed to detect cell apoptosis. The data shown are the means $\pm \mathrm{SD}$ of three independent experiments $\left({ }^{*} \mathrm{P}<0.05,{ }^{* * *} \mathrm{P}<0.01,{ }^{* * *} \mathrm{P}<0.001,{ }^{* * * *} \mathrm{P}<0.0001 \mathrm{vs}\right.$. the DMSO group).

C646, we observed a significant inhibitory effect on cell viability in GES-1 cells $(\mathrm{P}<0.05)$. Regarding the GC cell lines, the cell viability of SGC-7901, BGC-823 and KATO III showed no significant changes or even a slight elevation after treatment with 1 or $5 \mu \mathrm{mol} / 1 \mathrm{C} 646$. However, clear inhibition of cell viability was observed when these three GC cell lines were treated with higher concentrations of C646 $(\mathrm{P}<0.01)$. Additionally, treatment with 10,15 or $20 \mu \mathrm{mol} / 1 \mathrm{C} 646$ for $24 \mathrm{~h}$ showed a stronger inhibitory effect on the cell viability of these three GC cell lines than that of the GES-1 cell line; however, this results was not statistically significant. Regarding the MKN45 and MGC-803 cell lines, C646 demonstrated strong inhibitory effects on cell viability at all 5 concentrations $(\mathrm{P}<0.05)$. In addition, the cell viability of the MKN45 and MGC-803 cell lines decreased significantly compared with that of the GES-1 cell line $(\mathrm{P}<0.05)$. Furthermore, the number of apoptotic GC cells increased after treatment with C646 (Fig. 3B).
To further investigate the causes of cell viability inhibition, we assessed the cell cycle and cell apoptosis using flow cytometry. C646 $(10 \mu \mathrm{mol} / \mathrm{l})$ was added to the above 6 cell lines, and the cell cycle was evaluated after $6 \mathrm{~h}$. As displayed in Fig. 4A, the cell cycle of normal gastric epithelial GES-1 cells and GC MGC-803 cells was significantly blocked in $\mathrm{S}$ phase $(\mathrm{P}<0.001)$ and decreased number of cells were in $\mathrm{G} 2 / \mathrm{M}$ phase. However, the cell cycle of the other 4 GC cell lines was significantly arrested in the $\mathrm{G} 0 / \mathrm{G} 1$ phase $(\mathrm{P}<0.001)$ and reduced numbers of cells were in the $\mathrm{S}$ and $\mathrm{G} 2 / \mathrm{M}$ phases (Fig. 4A). Annexin V-FITC/PI staining was performed to detect the apoptotic cells of the above 6 cell lines after C646 treatment (10 $\mu \mathrm{mol} / \mathrm{l}$ for $24 \mathrm{~h}$ ). As shown in Fig. 4B, C646 significantly promoted the cell apoptosis of both normal gastric epithelial cell line and the 5 GC cell lines $(\mathrm{P}<0.05)$.

C646 prevents the migration and invasion of $G C$ cells. We performed a wound healing assay and found that C646 

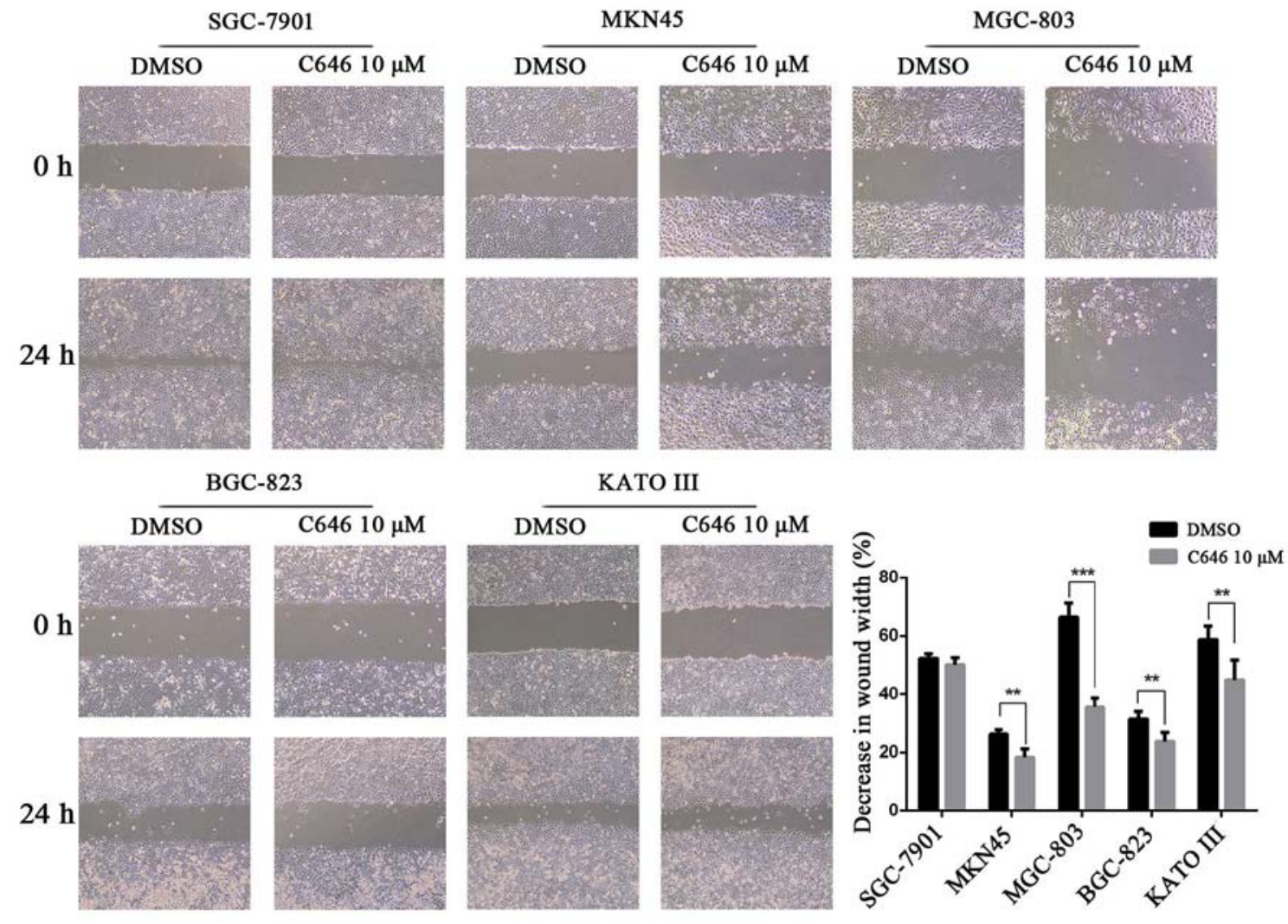

Figure 5. C646 treatment inhibits the migration of GC cells. A wound healing assay was performed to detect the cell migration ability of GC cells following the administration of $10 \mu \mathrm{mol} / 1 \mathrm{C} 646$ for $24 \mathrm{~h}$. The data shown are the means $\pm \mathrm{SD}$ of three independent experiments ${ }^{* * *} \mathrm{P}<0.01,{ }^{* * *} \mathrm{P}<0.001$ vs. the $\mathrm{DMSO}$ group).

significantly inhibited wound closure in the GC cells MKN45, MGC-803, BGC-823 and KATO III $(\mathrm{P}<0.01)$. However, the wound closure of SGC-7901 cells was not significantly affected by C646 compared with DMSO (Fig. 5). We also performed a Transwell assay with the GC cell lines following the administration of C646 $10 \mu \mathrm{mol} / 1$ for $24 \mathrm{~h}$. C646 treatment significantly reduced the number of invading cells in the MKN45, MGC-803, BGC-823 and KATO III cell lines $(\mathrm{P}<0.0001)$, whereas $\mathrm{C} 646$ treatment had the opposite effect in the SGC-7901 cell line $(\mathrm{P}<0.001)$ (Fig. 6).

C646 suppresses the expression of c-Met, cyclin D1, p-Akt, Bcl2, MMP7 and MMP9 in GC cells. According to previous studies, the tumourigenesis and development of GC were closely related to the receptor tyrosine kinase (RTK) c-Met (24-26). The activation of c-Met triggers signal transduction through the MAPK or PI3K/Akt/mTOR signalling pathways, which initiates cell proliferation and migration, regulates the cell cycle and reduces cell apoptosis (24). Erk 1/2 and Akt are key members of the MAPK and PI3K/Akt/mTOR signal pathways, respectively. cyclin D1 is a key protein that regulates the cell cycle. Accordingly, we investigated the protein expression of c-Met, cyclin D1, Erk 1/2 and Akt in 5 GC cell lines after C646 treatment. Surprisingly, C646 dramatically inhibited the expression of c-Met protein $(\mathrm{P}<0.01)$ (Fig. 7A). The mRNA level of $c$-Met was consistent with its protein expression level in MGC-803 cells, whereas no significant change or even an elevated trend was detected in the other $4 \mathrm{GC}$ cell lines (Fig. 7B). C646 (10 $\mu \mathrm{mol} / 1,6$ h) significantly downregulated cyclin D1 protein levels in the SGC-7901, MGC-803, BGC-823 and KATO III cell lines $(\mathrm{P}<0.05)$, but $\mathrm{C} 646$ treatment exhibited the opposite effect on cyclin D1 expression in MKN45 cells (Fig. 7A). We also observed a downregulation of total and phosphorylated Akt protein levels in the $5 \mathrm{GC}$ cell lines after C646 treatment. However, changes in total and phosphorylated Erk 1/2 levels showed the opposite trend (Fig. 8A).

Bcl-2, Bax and PARP are apoptosis-related proteins. In our experiments, we quantified the expression levels of these three proteins in the $5 \mathrm{GC}$ cell lines after C646 (10 $\mu \mathrm{mol} / \mathrm{l})$ treatment for $6 \mathrm{~h}$. C646 treatment decreased the ratio of $\mathrm{Bcl}-2 / \mathrm{Bax}$ expression in all of the $5 \mathrm{GC}$ cell lines $(\mathrm{P}<0.05)$. We also detected cleaved PARP in the SGC-7901, MKN45 and MGC-803 cell lines (Fig. 8B).

Finally, we measured the mRNA expression of matrix metalloprotease 7 (MMP7) and matrix metalloprotease 9 (MMP9) by qRT-PCR. As shown in Fig. 8C, in the MKN45 and KATO III cell lines, the results were consistent with an earlier study, and at least one of the two (MMP7 or MMP9) mRNA levels decreased after C646 treatment. Regarding the SGC-7901 cell line, the increased mRNA level of $M M P 9$ could explain its enhanced invasive ability. However, in contrast to previous results, the expression of MMPs mRNA was increased in the MGC-803 and BGC-823 cell lines.

\section{Discussion}

The histone acetyltransferases p300/CBP play crucial roles in several cell biology functions, such as the cell cycle, DNA 

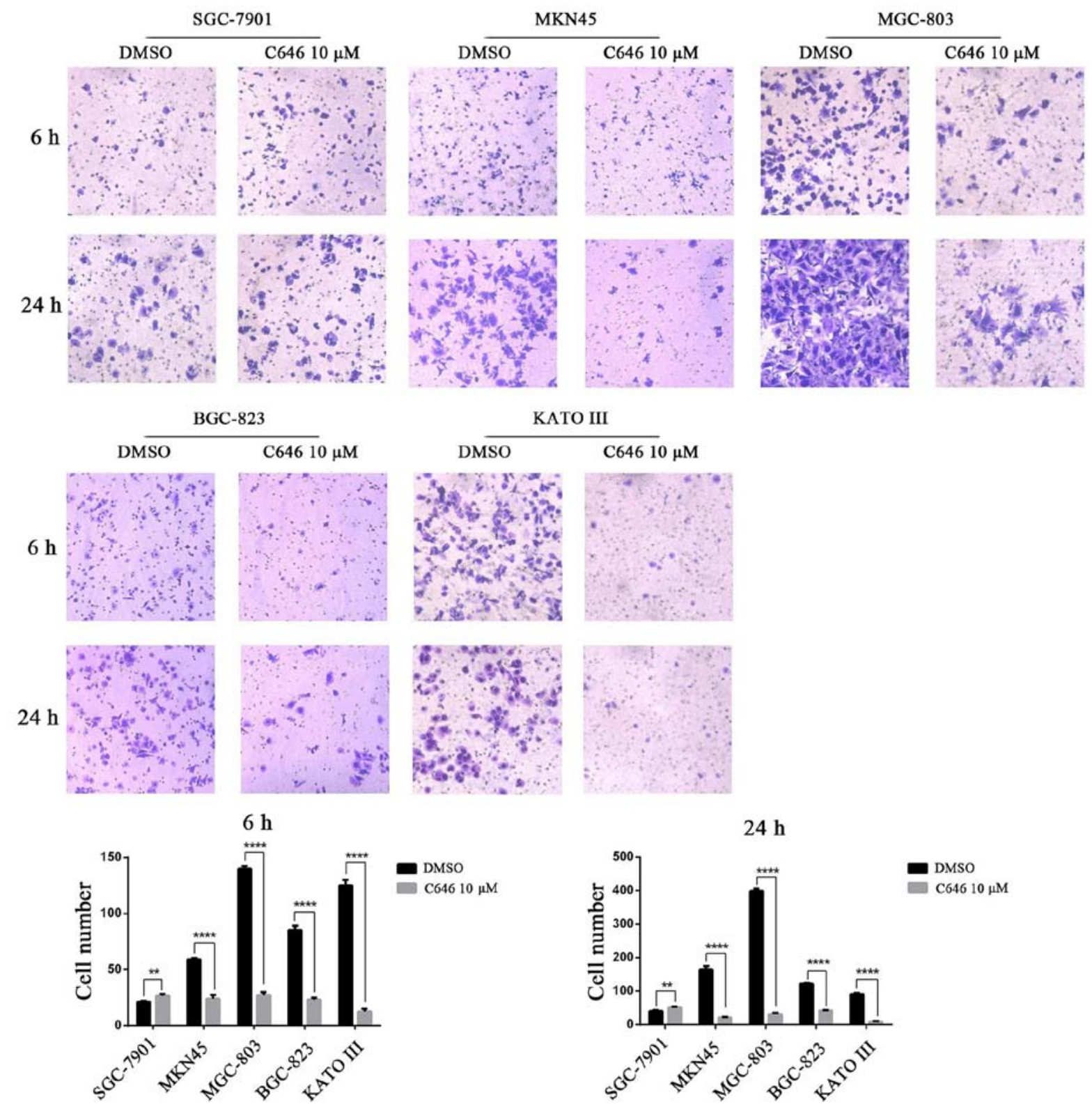

Figure 6. C646 prevents the invasion of gastric cancer cells. Transwell assay was conducted to evaluate the cell invasion ability of GC cells after treatment with $10 \mu \mathrm{mol} / 1 \mathrm{C} 646$ for 6 or $24 \mathrm{~h}$. The data shown are the means $\pm \mathrm{SD}$ of three independent experiments $\left({ }^{* *} \mathrm{P}<0.01,{ }^{* * * *} \mathrm{P}<0.0001 \mathrm{vs}\right.$. the DMSO group).
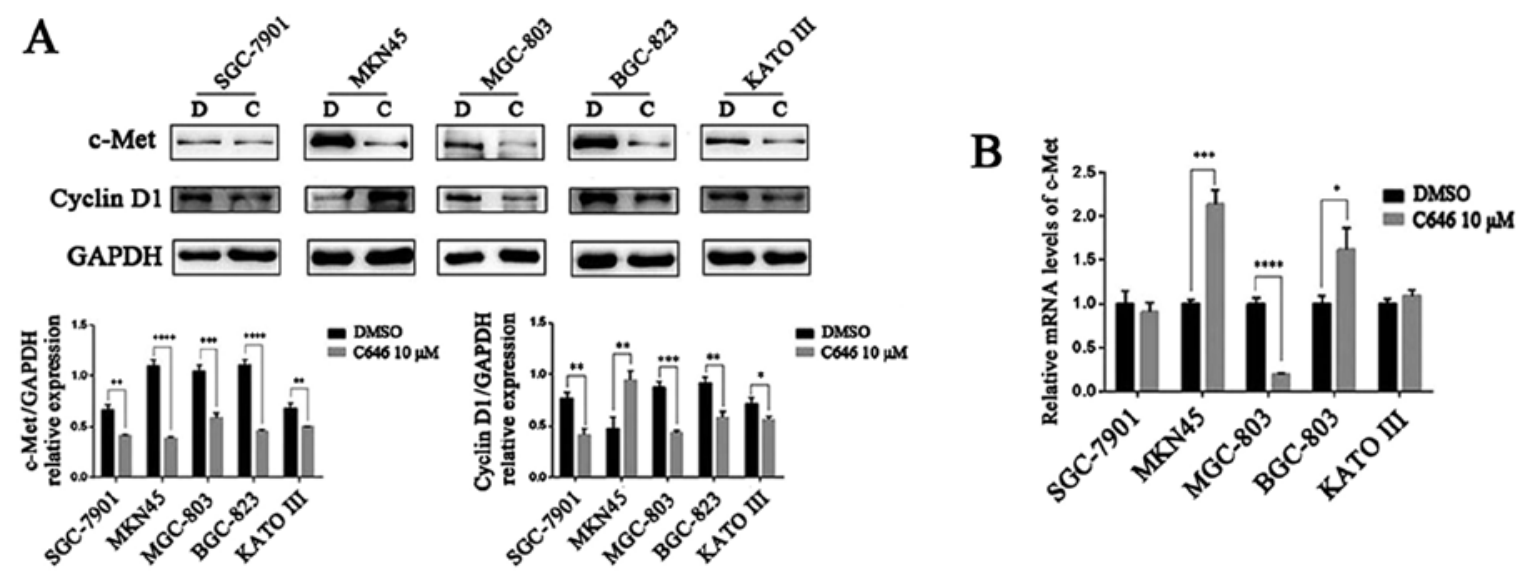

Figure 7. C646 reduced c-Met and cyclin D1 expression in GC cell lines. (A) GC cells were treated with $10 \mu \mathrm{mol} / 1 \mathrm{C} 646$ for $6 \mathrm{~h}$. Western blotting was conducted to detect the c-Met and cyclin D1 protein expression. (B) GC cell lines were exposed to $10 \mu \mathrm{mol} / 1 \mathrm{C} 646 \mathrm{for} 24 \mathrm{~h}$. qRT-PCR was performed to determine the

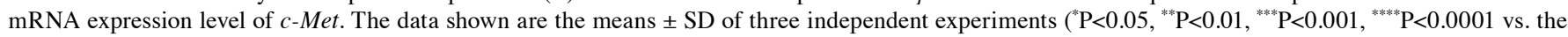
DMSO group). D, DMSO; C, C646. 
A
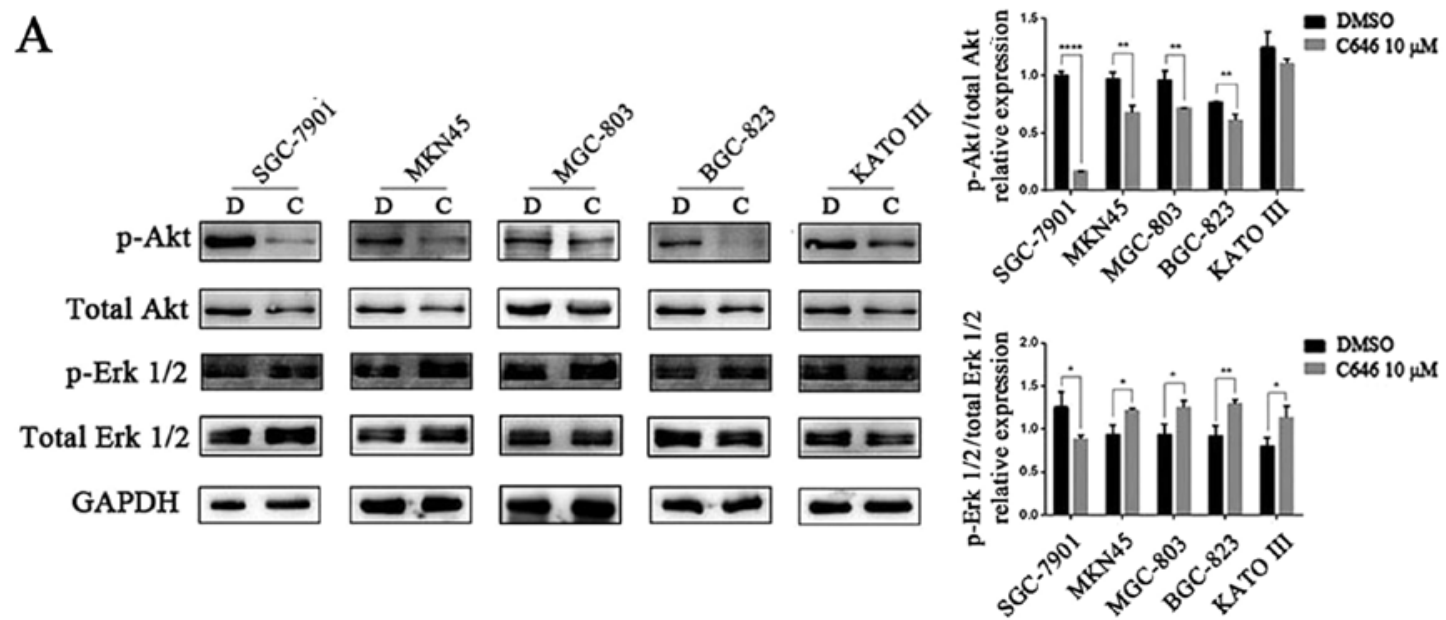

B
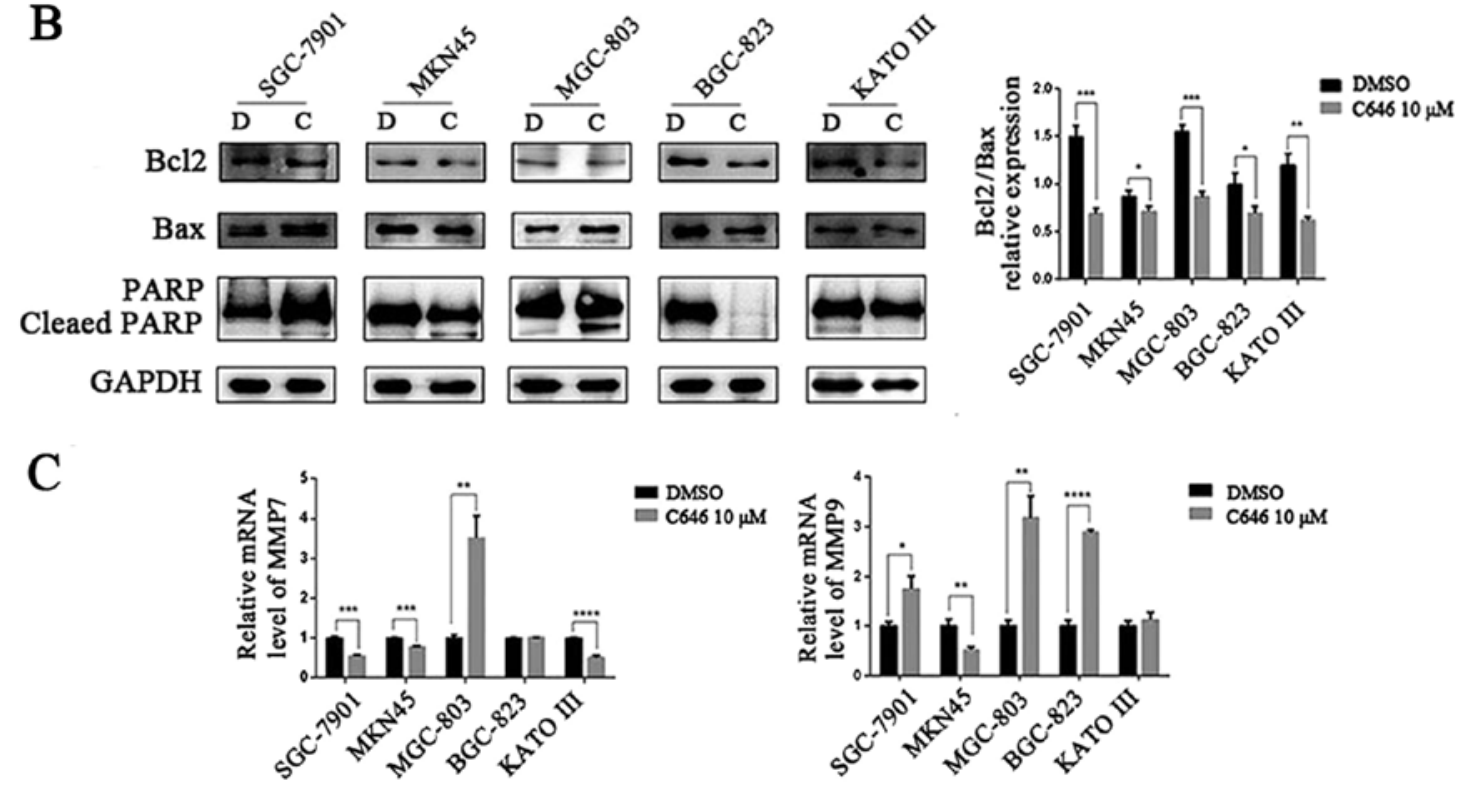

Figure 8. C646 activates the apoptotic pathway in all $5 \mathrm{GC}$ cell lines and inhibits MMP expression in some of the GC cell lines. (A) After treatment with $10 \mu \mathrm{mol} / 1 \mathrm{C} 646$ for $6 \mathrm{~h}$, the protein expression levels of p-Akt, total Akt, p-Erk 1/2 and total Erk 1/2 in GC cell lines were detected by western blotting. (B) GC cell lines were exposed to $10 \mu \mathrm{mol} / 1 \mathrm{C} 646$ for $6 \mathrm{~h}$. Western blotting was conducted to quantify the protein expression levels of Bcl2, Bax and PARP. (C) After treatment with $10 \mu \mathrm{mol} / 1 \mathrm{C} 646$ for $24 \mathrm{~h}, \mathrm{qRT}-\mathrm{PCR}$ was performed to determine the mRNA expression levels of $M M P 7$ and $M M P 9$ in GC cells. The data shown are the means $\pm \mathrm{SD}$ of three independent experiments $\left({ }^{*} \mathrm{P}<0.05,{ }^{* *} \mathrm{P}<0.01,{ }^{* * *} \mathrm{P}<0.001,{ }^{* * * * *} \mathrm{P}<0.0001\right.$ vs. the DMSO group). D, DMSO; C, C646.

synthesis and cellular differentiation (5,7). p300/CBP could acetylate histones and non-histone proteins to suppress or promote tumourigenesis and malignancy $(22,23)$. p300/CBP are thought to contribute to the development of many tumours, such as leukaemia, human prostate, colon, melanoma and pancreatic cancer $(11-13,17,27)$. However, the differences in p300/CBP expression between normal gastric epithelial cells and GC cells have rarely been reported. In the present study, p300/CBP proteins were upregulated in 5 GC cell lines, and the mRNA expression of $p 300 / C B P$ was also upregulated in GC cells (except MGC-803 cells) compared with normal gastric epithelial cells, indicating that $\mathrm{p} 300 / \mathrm{CBP}$ play important roles in the tumourigenesis of GC.

To investigate the effects of $\mathrm{p} 300 / \mathrm{CBP}$ on GC cell lines, we used C646, a selective inhibitor of p300/CBP. C646 treatment supressed cell viability and induced cell apoptosis in both normal gastric epithelial cells and the 5 GC cell lines. The inhibition of cell viability in normal gastric epithelial cells by
C646 was not as strong as that of GC cells. We speculate that there are two reasons for this outcome. First, both GC cells and normal gastric epithelial cells express p300/CBP, but their expression levels are lower in normal gastric epithelial cells than in GC cells. Second, the expression level of Ac-H3 in GC cell lines is higher than that in the GES-1 cell line, suggesting that p300/CBP are excessively activated in GC cells. In addition, we observed that $\mathrm{C} 646$ exhibited the strongest inhibitory effects toward poorly differentiated GC cells (MKN45 and MGC-803).

In addition, $\mathrm{C} 646$ blocked the cell cycle in the $\mathrm{G} 0 / \mathrm{G} 1$ phase in SGC-7901, MKN45, BGC-823 and KATO III GC cells. This outcome is consistent with a previous study (19). However, the cell cycle was arrested in $\mathrm{S}$ phase in normal gastric epithelial GES-1 cells and GC MGC-803 cells, indicating that the cell cycle is differentially impacted by $\mathrm{C} 646$ in different cell lines. The migration and invasion of most GC cell lines were inhibited, but those biological functions were not affected or even 
enhanced by C646 in the SGC-7901 cell line. The disparate influences of $\mathrm{C} 646$ on the migration and invasion ability of different GC cells may be related to the degree of cell differentiation. SGC-7901 is a moderately differentiated GC cell line, however, the other GC cells were poorly differentiated (MKN45 and MGC-803), undifferentiated (BGC-823) or classified as signet-ring cancer cells (KATO III). C646 represents a potential new drug for patients with $\mathrm{GC}$, especially poorly differentiated GC. However, for moderately differentiated GC, C646 was more likely to promote tumourigenesis and progression.

c-Met, a receptor tyrosine kinase, plays a crucial role in the tumourigenesis and development of GC (24-26). We detected the protein levels of c-Met and its downstream signalling molecules Akt and Erk 1/2. The protein expression of c-Met, as well as that of total and phosphorylated Akt, was downregulated after treatment with C646 in all 5 GC cell lines. Moreover, C646 treatment led to decreased mRNA expression of $c$-Met in MGC-803 cells. However, in the other 4 GC cell lines, the $c$-Met mRNA expression levels were unchanged or even elevated. MicroRNAs (miRNAs) have been reported to be involved in regulating the expression of many cellular functional genes at the post-transcriptional levels $(1,28)$. Studies have demonstrated that miRNAs inhibited the cell proliferation, invasion and migration of GC cells by directly targeting the c-Met gene and downregulating its expression (29-31). Thus, we speculate that C646 regulates the expression of c-Met at the transcriptional level (for MGC-803 cells) or posttranscriptional level (for SGC-7901, MKN45, BGC-823 and KATO III cells) and further regulates cell proliferation, migration, the cell cycle and apoptosis through the Akt signalling pathway. The expression level of phosphorylated Erk 1/2 was found to be increased after C646 treatment in many of the GC cell lines; however, the exact mechanism underlying this phenomenon is unclear. Changes in p-Erk $1 / 2$ expression under the stimulation of some compounds has been reported within $1 \mathrm{~h}(32,33)$. We suspect that the reversed expression of p-Erk $1 / 2$ observed in the present study may be related to our experimental time-point.

p300/CBP can enhance the transcription of cyclin DI and promote G1-S cell cycle progression (34). To investigate whether the cell cycle arrest of GC cell lines was associated with cyclin D1 expression, we performed a western blot assay. As expected, the expression of cyclin D1 protein was inhibited by C646 in the GC cell lines SGC-7901, MGC-803, BGC-823 and KATO III. Thus, C646 blocked the cell cycle in these 4 GC cell lines by inhibiting cyclin D1 expression. Notably, C646 arrested the G0/G1 phase of the MKN45 cell line but could not inhibit cyclin D1 expression, suggesting that other cyclins may also participate in the regulation of the cell cycle in different GC cells.

Bcl-2 is an important anti-apoptotic protein and Bax is a crucial pro-apoptotic protein. Apoptotic activity can be reflected by the ratio of $\mathrm{Bcl}-2 / \mathrm{Bax}$ (24). The nuclear enzyme poly(ADP-ribose) polymerase (PARP) is a key modulator of the apoptotic pathway, which can be proteolytically cleaved by caspase-3/7 when cell apoptosis occurs (35). In the present study, C646 treatment decreased the ratio of Bcl-2/Bax in the 5 GC cell lines. In addition, cleaved PARP was discovered in SGC-7901, MKN45 and MGC-803 cells.
Consequently, C646 may induce apoptosis of GC cells through different pathways.

As members of the matrix metalloproteinase family, MMP7 and MMP9 are involved in tumour metastasis, and their expression is associated with the invasion activity of cancer cells. The expression of MMP7 and MMP9 mRNA was detected in $5 \mathrm{GC}$ cells after C646 treatment. For the SGC-7901, MKN45 and KATO III cell lines, the MMP expression trends could explain the previous migration and invasion results. While C646 increased the mRNA expression of MMP7 and (or) MMP9 in the BGC-823 and MGC-803 cell lines, the results are inconsistent with previous reports. Tumour metastasis is a highly complex process that is closely associated with EMT. He et al (36) found that mesothelin (MSLN) played an essential role in cell adhesion, migration and invasion of many solid tumour cells (such as human lung cancer cells and mesothelioma cells) by regulating EMT. In addition, reports have revealed that MSLN is expressed in many GCs and associated with lymphatic involvement, tumour invasion and the 5-year survival rate of GC patients (37-39). We speculate that C646 might affect the migration and invasion of MGC-803 and BGC-823 cells by regulating the expression of MSLN or other MMPs that were not quantified in the present study.

In conclusion, p300/CBP might contribute to the carcinogenesis and development of GC. The p300/CBP inhibitor C646 inhibited cell growth, blocked the cell cycle and promoted cell apoptosis in GC cells by regulating the c-Met/Akt pathway and the expression of Bcl2, PARP and cyclin D1. Additionally, C646 exhibited a potent inhibitory effect on migration and invasion in poorly differentiated, undifferentiated or signetring GC cells. Based on these results, C646 is a potential treatment for multi-type (except the moderately differentiated type) GC.

\section{Acknowledgements}

The present study was supported by the Scientific Research Foundation of the National Health and Family Planning Commission of the People's Republic of China (WKJ-ZJ-1614). We are very grateful to the State Key Laboratory for the Diagnosis and Treatment of Infectious Diseases of the First Affiliated Hospital of Zhejiang University for providing excellent technical assistance.

\section{References}

1. Tan P and Yeoh KG: Genetics and molecular pathogenesis of gastric adenocarcinoma. Gastroenterology 149: 1153-1162.e3, 2015.

2. Meyer $\mathrm{HJ}$ and Wilke $\mathrm{H}$ : Treatment strategies in gastric cancer. Dtsch Arztebl Int 108: 698-705, 706, 2011.

3. Saka M, Morita S, Fukagawa T and Katai H: Present and future status of gastric cancer surgery. Jpn J Clin Oncol 41: 307-313, 2011.

4. Giles RH, Peters DJ and Breuning MH: Conjunction dysfunction: CBP/p300 in human disease. Trends Genet 14: 178-183, 1998.

5. Roth SY, Denu JM and Allis CD: Histone acetyltransferases. Annu Rev Biochem 70: 81-120, 2001.

6. Shiama N: The p300/CBP family: Integrating signals with transcription factors and chromatin. Trends Cell Biol 7: 230-236, 1997.

7. Giordano A and Avantaggiati ML: p300 and CBP: Partners for life and death. J Cell Physiol 181: 218-230, 1999. 
8. Chan HM and La Thangue NB: p300/CBP proteins: HATs for transcriptional bridges and scaffolds. J Cell Sci 114: 2363-2373, 2001.

9. Debes JD, Sebo TJ, Lohse CM, Murphy LM, Haugen DA and Tindall DJ: p300 in prostate cancer proliferation and progression. Cancer Res 63: 7638-7640, 2003.

10. Linja MJ, Porkka KP, Kang Z, Savinainen KJ, Jänne OA, Tammela TL, Vessella RL, Palvimo JJ and Visakorpi T: Expression of androgen receptor coregulators in prostate cancer. Clin Cancer Res 10: 1032-1040, 2004

11. Santer FR, Höschele PP, Oh SJ, Erb HH, Bouchal J, Cavarretta IT, Parson W, Meyers DJ, Cole PA and Culig Z: Inhibition of the acetyltransferases p300 and CBP reveals a targetable function for p300 in the survival and invasion pathways of prostate cancer cell lines. Mol Cancer Ther 10: 1644-1655, 2011.

12. Iyer NG, Chin SF, Ozdag H, Daigo Y, Hu DE, Cariati M, Brindle K, Aparicio S and Caldas C: p300 regulates p53-dependent apoptosis after DNA damage in colorectal cancer cells by modulation of PUMA/p21 levels. Proc Natl Acad Sci USA 101: 7386-7391, 2004.

13. Lin WM, Baker AC, Beroukhim R, Winckler W, Feng W Marmion JM, Laine E, Greulich H, Tseng H, Gates C, et al: Modeling genomic diversity and tumor dependency in malignant melanoma. Cancer Res 68: 664-673, 2008.

14. Garraway LA, Widlund HR, Rubin MA, Getz G, Berger AJ, Ramaswamy S, Beroukhim R, Milner DA, Granter SR, Du J, et al: Integrative genomic analyses identify MITF as a lineage survival oncogene amplified in malignant melanoma. Nature 436: 117-122, 2005.

15. Sato S, Roberts K, Gambino G, Cook A, Kouzarides T and Goding CR: CBP/p300 as a co-factor for the Microphthalmia transcription factor. Oncogene 14: 3083-3092, 1997.

16. Yajima I, Kumasaka MY, Thang ND, Goto Y, Takeda K, Iida M, Ohgami N, Tamura H, Yamanoshita $\mathrm{O}$, Kawamoto Y, et al Molecular Network associated with MITF in skin melanoma development and progression. J Skin Cancer 2011: 730170, 2011.

17. Paladino D, Yue P, Furuya H, Acoba J, Rosser CJ and Turkson J: A novel nuclear Src and p300 signaling axis controls migratory and invasive behavior in pancreatic cancer. Oncotarget 7: 7253-7267, 2015.

18. Han RF, Ji X, Dong XG, Xiao RJ, Liu YP, Xiong J and Zhang QP: An epigenetic mechanism underlying doxorubicin induced EMT in the human BGC-823 gastric cancer cell. Asian Pac J Cancer Prev 15: 4271-4274, 2014

19. Gao XN, Lin J, Ning QY, Gao L, Yao YS, Zhou JH, Li YH, Wang LL and Yu L: A histone acetyltransferase p300 inhibitor C646 induces cell cycle arrest and apoptosis selectively in AML1-ETO-positive AML cells. PLoS One 8: e55481, 2013.

20. Gu ML, Wang YM, Zhou XX, Yao HP, Zheng S, Xiang Z and Ji F: An inhibitor of the acetyltransferases CBP/p300 exerts antineoplastic effects on gastrointestinal stromal tumor cells. Oncol Rep 36: 2763-2770, 2016.

21. Zhang Y, Gu ML, Zhou XX, Ma H, Yao HP and Ji F: Altered expression of ETV1 and its contribution to tumorigenic phenotypes in gastrointestinal stromal tumors. Oncol Rep 32: 927-934, 2014.

22. Friedmann DR and Marmorstein R: Structure and mechanism of non-histone protein acetyltransferase enzymes. FEBS J 280 5570-5581, 2013

23. Wang L, Gural A, Sun XJ, Zhao X, Perna F, Huang G, Hatlen MA, $\mathrm{Vu} \mathrm{L}$, Liu F, Xu H, et al: The leukemogenicity of AML1-ETO is dependent on site-specific lysine acetylation. Science 333: $765-769,2011$
24. Wu Y, Yao X, Zhu M, Qian H, Jiang L, Lan T, Wu M, Pang J and Chen Y: PKG II reverses HGF-triggered cellular activities by phosphorylating serine 985 of c-Met in gastric cancer cells. Oncotarget 7: 34190-34200, 2016.

25. Marano L, Chiari R, Fabozzi A, De Vita F, Boccardi V, Roviello G, Petrioli R, Marrelli D, Roviello F and Patriti A: c-Met targeting in advanced gastric cancer: An open challenge. Cancer Lett 365: 30-36, 2015.

26. Fuse N, Kuboki Y, Kuwata T, Nishina T, Kadowaki S, Shinozaki E, Machida N, Yuki S, Ooki A, Kajiura S, et al: Prognostic impact of HER2, EGFR, and c-MET status on overall survival of advanced gastric cancer patients. Gastric Cancer 19: 183-191, 2016.

27. Katsumoto T, Yoshida N and Kitabayashi I: Roles of the histone acetyltransferase monocytic leukemia zinc finger protein in normal and malignant hematopoiesis. Cancer Sci 99: 1523-1527, 2008.

28. Lu YF, Zhang L, Waye MM, Fu WM and Zhang JF: MiR-218 mediates tumorigenesis and metastasis: Perspectives and implications. Exp Cell Res 334: 173-182, 2015.

29. Li S, Zhang H, Wang X, Qu Y, Duan J, Liu R, Deng T, Ning T, Zhang L, Bai M, et al: Direct targeting of HGF by miR-16 regulates proliferation and migration in gastric cancer. Tumour Biol 37: 15175-15183, 2016

30. Wei B, Huang QY, Huang SR, Mai W and Zhong XG: MicroRNA-34a attenuates the proliferation, invasion and metastasis of gastric cancer cells via downregulation of MET. Mo Med Rep 12: 5255-5261, 2015.

31. Han C, Zhou Y, An Q, Li F, Li D, Zhang X, Yu Z, Zheng L, Duan Z and Kan Q: MicroRNA-1 (miR-1) inhibits gastric cancer cell proliferation and migration by targeting MET. Tumour Biol 36: 6715-6723, 2015.

32. Ji Z, Su J, Liu C, Wang H, Huang D and Zhou X: Integrating genomics and proteomics data to predict drug effects using binary linear programming. PLoS One 9: e102798, 2014.

33. Kholodenko BN, Demin OV, Moehren G and Hoek JB: Quantification of short term signaling by the epidermal growth factor receptor. J Biol Chem 274: 30169-30181, 1999.

34. Lee HR, Mitra J, Lee S, Gao SJ, Oh TK, Kim MH, Ha T and Jung JU: Kaposi's sarcoma-associated herpesvirus viral interferon regulatory factor 4 (vIRF4) perturbs the G1-S cell cycle progression via deregulation of the cyclin D1 gene. J Virol 90 : $1139-1143,2015$

35. Gao H, Wu B, Le Y and Zhu Z: Homeobox protein VentX induces p53-independent apoptosis in cancer cells. Oncotarget 7: 39719-39729, 2016

36. He X, Wang L, Riedel H, Wang K, Yang Y, Dinu CZ and Rojanasakul Y: Mesothelin promotes epithelial-to-mesenchymal transition and tumorigenicity of human lung cancer and mesothelioma cells. Mol Cancer 16: 63, 2017.

37. Ito T, Kajino K, Abe M, Sato K, Maekawa H, Sakurada M, Orita H, Wada R, Kajiyama Y and Hino O: ERC/mesothelin is expressed in human gastric cancer tissues and cell lines. Oncol Rep 31: 27-33, 2014

38. Einama T, Homma S, Kamachi H, Kawamata F, Takahashi K, Takahashi N, Taniguchi M, Kamiyama T, Furukawa H, Matsuno Y, et al: Luminal membrane expression of mesothelin is a prominent poor prognostic factor for gastric cancer. $\mathrm{Br} J$ Cancer 107: 137-142, 2012.

39. Baba K, Ishigami S, Arigami T, Uenosono $\mathrm{Y}$, Okumura $\mathrm{H}$, Matsumoto M, Kurahara H, Uchikado Y, Kita Y, Kijima Y, et al: Mesothelin expression correlates with prolonged patient survival in gastric cancer. J Surg Oncol 105: 195-199, 2012. 